\title{
A Situação de Saúde dos Índios Yanomámi: Diagnóstico a Partir da Casa do Índio de Boa Vista, Roraima, 1987 - 1989
}

Relata-se a evolução dos perfis de morbidade de indios da etnia Yanomámi atendidos na Casa do Indio na cidade de Boa Vista, Roraima, no periodo de janeiro de 1987 a agosto de 1989. Dentre 495 internações, constatou-se que os principais agravos observados foram, em ordem descrescente, a malária, as infeç̧ões respiratórias agudas, a tuberculose, a desnutriçāo grave $e$ as doenças sexualmente transmissiveis. Dentre os 114 óbitos, a malária foi a causa principal nos três anos estudados. Foi observado um aumento importante na freqüência das internações de pacientes provenientes das áreas com maior concentração de garimpos de ouro. Discute-se o impacto global da invasão garimpeira na qualidade de vida e nos niveis de saúde da população Yanomámi.

\section{INTRODUÇÃO}

Os indios Yanomámi, localizados, no Brasil, nọs estados do Amazonas e Roraima, e também na Venezuela, constituem o maior grupo tribal semi-isolado da América do Sul. Do lado brasileiro, até 1987, o seu território tradicional, que se estende por uma área de cerca de $94.500 \mathrm{Km}^{2}$, continha uma população total de cerca de 9 mil indivíduos. Estes tinham contato sistemático apenas com um reduzido número de não-índios, representados por funcionários de agências assistenciais governamentais e

- Fundação Nacional de Saúde, Ministério da Saude, Boa Vista, Roraima - 69300.

** Núcleo de-Estudos em Sauide de Populações Indigenas, Escola Nacional de Saude Pública (Ensp/Fiocruz), Avenida Brasil 4036, sala 707, 21040, Rio de Janeiro, RJ, Brasil.

*" Departamento de Epidemiologia e Métodos Quantitativos em Saúde da Ensp/Fiocruz, $R$ Leopoldo Bulhöes, 1.480, $8^{\circ}$ andar, 21041, Rio de Janeiro, $R J$. 
não governamentais e, de forma intermitente, com poucos extrativistas ou equipes de cientistas e jornalistas. A partir de agosto de 1987, houve uma invasão súbita e maciça da área por garimpeiros em busca de ouro. As conseqüências sócio-culturais, ambientais e sanitárias deste processo se fizeram visíveis com rapidez.

No aspecto de saúde, o reflexo imediato foi o brusco aumento do fluxo de pacientes desta etnia para atendimento médico na Casa do Indio de Boa Vista (CIBV), pertencente à Fundação Nacional do Índio (Funai), em Roraima.

O presente trabalho é um relato do perfil de morbi-mortalidade dos índios Yanomámi atendidos pela equipe da CIBV, do período imediatamente anterior à invasão garimpeira até os dois anos subseqüentes à mesma, a partir de dados condensados em relatório anterior (Pithan, 1989).

\section{MATERIAL E MÉTODOS}

O periodo incluído neste estudo vai de janeiro de 1987 a agosto de 1989. Todos os pacientes da etnia Yanomámi atendidos na CIBV neste lapso de tempo tiveram seus prontuários investigados. Foi dada atenção específica às informações relativas às sub-regiões de procedência dos pacientes e à natureza das afeç̧ões diagnosticadas em cada um deles, bem como àquelas causadoras de óbitos na população Yanomámi em geral.

No que tange às enfermidades diagnosticadas e incluídas na análise, foram consideradas principalmente aquelas que apresentaram um caráter de maior gravidade, capazes de justificar a internação. Entretanto, no total de "diagnósticos" computados para o registro da multimorbidade, foram incluídas também condições secundárias bem individualizadas c que faziam parte do quadro geral de deterioração dos níveis de saúde atribuídos às relações de contato com a população invasora. Por isto, afeç̧ões como a oncocercose, sabidamente disseminada há décadas na população Yanomámi, de caráter crônico, de impacto lesional limitado e diagnóstico mais difícil, não foram consideradas na análise. 
Para uma comparação, por sub-regiões, da origem dos pacientes atendidos, foram consideradas duas categorias: regiões de alta concentração e de baixa concentração de garimpeiros, sendo estas últimas aquelas que continham menos de 200 invasores. Trata-se de uma estimativa aproximada de densidade garimpeira baseada na experiência de trabalho de campo dos autores, bem como em informações colhidas com outros agentes que trabalhavam na região, complementadas com dados da imprensa. Foram assim identificadas três microrregiões de procedência de pacientes com baixa concentração garimpeira (Catrimani, Demini e Ajarani) e três microrregiões de alta concentração (Paapiú, Mucajaí e Ericó).

A estimativa populacional para cada grupamento Yanomámi citado foi feita a partir de dados levantados em 1988.

Quanto aos dados de mortalidade dos Yanomámi, também foram incluídos no estudo óbitos ocorridos fora da CIBV, tendo as informações sido obtidas nos registros dos postos indígenas da Funai na área Yanomámi, na Missão Consolata do Catrimani e nos arquivos da Secretaria de Estado de Saúde de Roraima.

\section{RESULTADOS}

Foi avaliado um total de 495 registros de internacões de índios Yanomámi no período do estudo. Em relação às seis outras etnias nativas no estado de Roraima, houve aumento importante na participação no total geral de internaçōes, passando de $15,7 \%$ ( 83 dentre 526 pacientes), em 1987, para 57,8\% (214 em 370 pacientes), em 1988, e 39,3\% (198 em 503 pacientes) de janeiro a agosto de 1989

A Figura I mostra, de 1987 a 1989, o percentual da etnia Yanomámi de Roraima que foi hospitalizada na CIBV, em comparação com o percentual das outras seis etnias. O impacto foi incontestável e visivel apenas de 1988 em diante, em função do fluxo de garimpeiros ter se dado a partir de agosto de 1987. 
Freqüència de Indígenas Yanomámi e de Outras Etnias Hospitalizados na CIBV de JAN de 87 a AGO 89 (No Topo da Coluna, Percentual Relativo à População da Etnia)

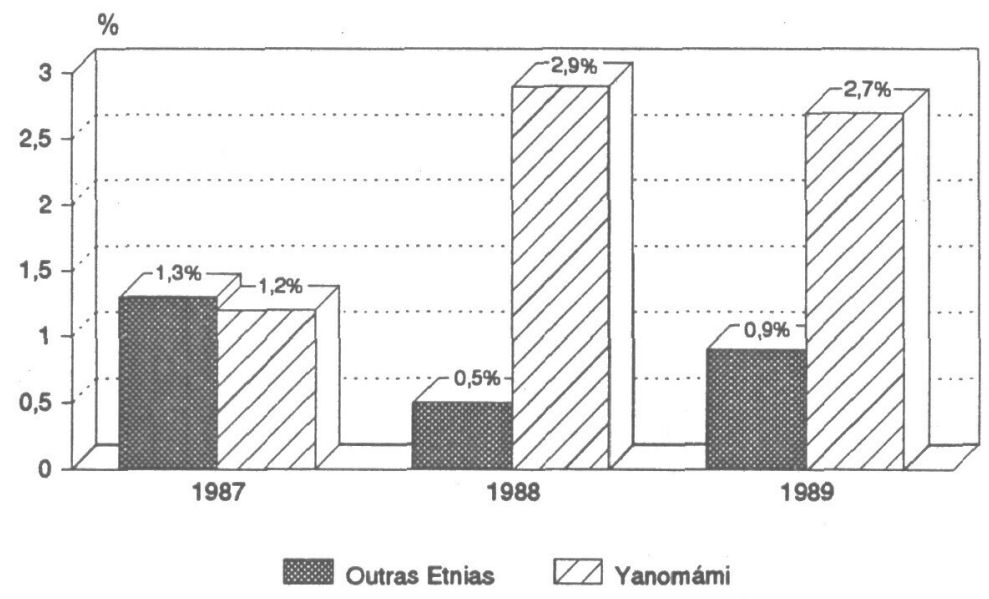

CIBV - Casa do Indio de Boa Vista

* Estimativa para 1988

No levantamento de atendimento por sub-regiões (Tabela I), verifica-se uma crescente concentração de casos procedentes da sub-região do Mucajaí, atingindo $42,0 \%$ de sua população hospitalizada de 1987 a 1989, seguida da região do Paapiú, com $40,0 \%$ neste mesmo período. Por outro lado, regiões praticamente livres da invasão garimpeira, como, por exemplo, a do Catrimani, tiveram, em 1987/1989, 4,5\% de sua população hospitalizada.

Comparando-se os indices ano a ano, verifica-se, na região do Paapiú, um importante aumento de hospitalizações, que passaram de $1,6 \%$ da população das aldeias em 1987 para 22,1\% em 1989. 


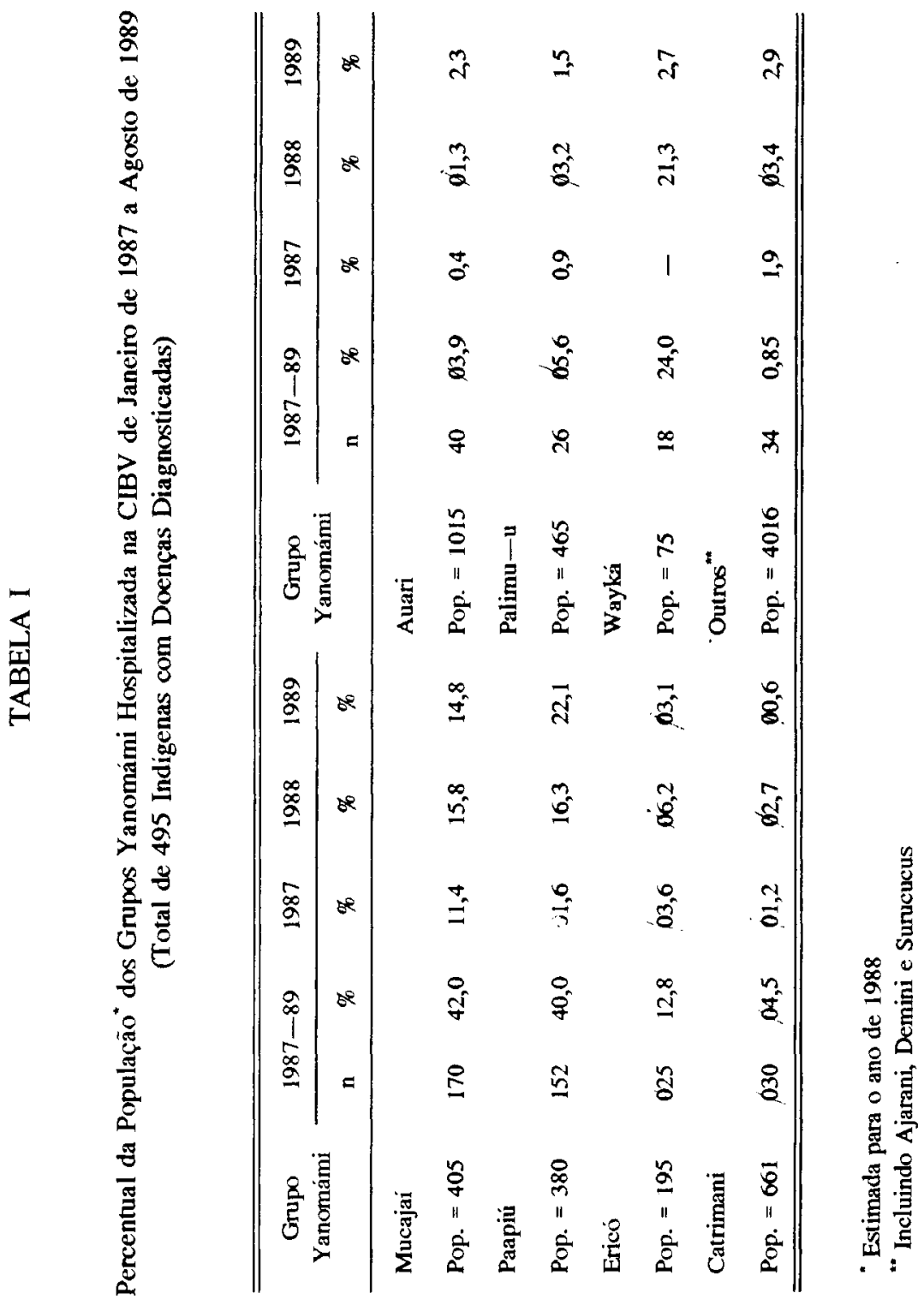


Quanto ao perfil de morbidade, nota-se que a malária foi diagnosticada num maior número de casos, seguida de infecções respiratórias agudas, tuberculose, desnutrição, doenças sexualmente transmissíveis (Figura II) e processos infecciosos gastroentéricos.

\section{FIGURA II}

Doenças Graves que Mais Hospitalizaram Indigenas

Yanomámi na CIBV de JAN 87 a AGO 89

(NNo Exato de Casos no topo da Coluna)

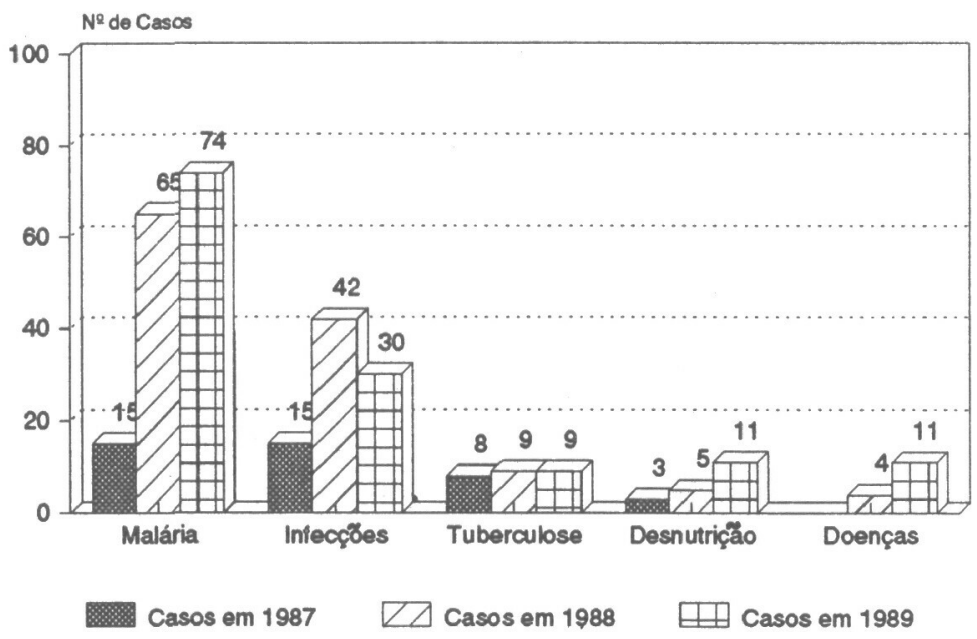

Sob a perspectiva global, tomando-se dois grupos de comunidades, um com pouca e outro com muita influência do garimpo, constata-se que o percentual de hospitalizaçōes por grupo é maior naquele com alta concentração de garimpos nos três anos estudados (Figura III). 


\section{FIGURA III}

Indígenas Yanomámi Hospitalizados na CIBV, Classificados

Segundo a Concentração de Garimpeiros no Peridomicílio

(No Topo da Coluna, \% de Casos em Relação

à População da Etnia)

de Garimpeiros *

de Garimpeiros * *

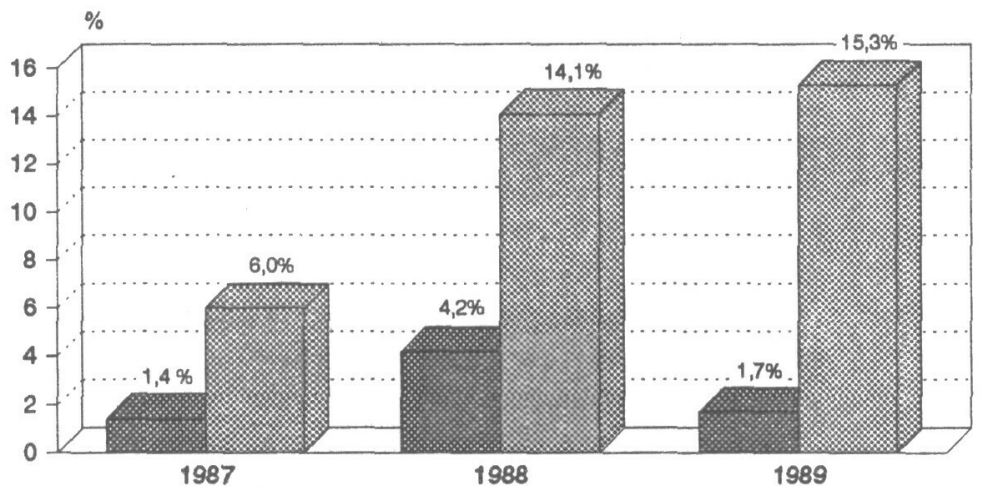

Baixa Concentiação Alta Concentração

\section{Casa do Índio de Boa Vista}

- Ajarani, Catrimani, Demini, (População Aproximada de 763 Indígenas)

"- Paapiú, Mucajai, Ericó, (População Aproximada de 980 Indígenas)

A infecção malárica, de grande relevância epidemiológica pelo número de casos e abrangência de sua dispersão, teve um aumento de cerca de $500 \%$ na sua ocorrência entre 1987 e 1989. Dos 74 casos atendidos em 1989, 38 (oụ $51,3 \%$ ) apresentaram anemia severa, sendo que em 17 dos casos, pela sua gravidade (hemoglobina $<9 \%$ e/ou hematócrito $30 \%$ ), houve necessidade de transfusão sangüínea. Cumpre ressaltar ainda que, analisando-se a procedência dos Yanomámi que foram tratados de malária em 1989, constatamos que 50\% dos casos eram da região do Paapiú, onde, até 1987, não havia registro de transmissão local dessa parasitose. 
Quanto a infeç̧ões respiratórias agudas, nota-se que os casos praticamente triplicaram de 1987 (15 casos) para 1989 (42 casos) e, nos primeiros meses de 1989 (30 casos), já somavam o dobro do número de casos de 1987.

No que se refere à desnutrição grave, vê-se que, além do número de casos ter se multiplicado a partir de 1987 , neste ano o problema foi identificado em três adultos, enquanto que dos 16 casos internados a partir de 1988, 11 foram ein menores de cinco anos de idade.

Ao se analisar a região de procedência dos pacientes acometidos pelos principais processos mórbidos identificados - malária, pneumonia e doenças sexualmente transmissiveis (DST), verifica-se também uma maior concentração de casos em áreas de maior atividade garimpeira. Nota-se a ausência de DST, nos três anos considerados, nas áreas não invadidas (Figura IV).

Estes dados são particularmente importantes porque se tratam de doenças de grande impacto e cuja ligação com a presença garimpeira é clara.

No que tange à multimorbidade, verifica-se que $56,6 \%$ dos pacientes Yanomámi tiveram mais de uma afeç̧ão durante a internação, dos quais $26,4 \%$ apresentaram 3 ou mais agravos (Tabela II).

\section{TABELA II}

Indigenas Yanomámi Hospitalizados na CIBV entre Janeiro de 1987 a Agosto de 1989 Distribuídos Pelo № de Doenças Diagnosticadas em Cada Paciente

\begin{tabular}{l|cccc}
\hline \hline No de Diagnósticos & № & \% & \\
\hline Apenas um & 215 & & 43,4 & \\
Mais de um & 280 & & 56,6 & \\
\multicolumn{1}{c|}{ com dois } & & 168 & & 60,0 \\
\multicolumn{1}{c}{ com três } & & 74 & 26,4 \\
$\quad$ com 4 ou mais & & 38 & & 13,6 \\
\hline Total & 495 & & 100,0 & \\
\hline \hline
\end{tabular}


FIGURA IV

Indígenas Yanomámi Hospitalizados por Três Doenças Graves na CIBV, Classificados Segundo a Concentração de Garimpeiros no Peridomicílio dos Indígenas (№ de casos no topo da Coluna)

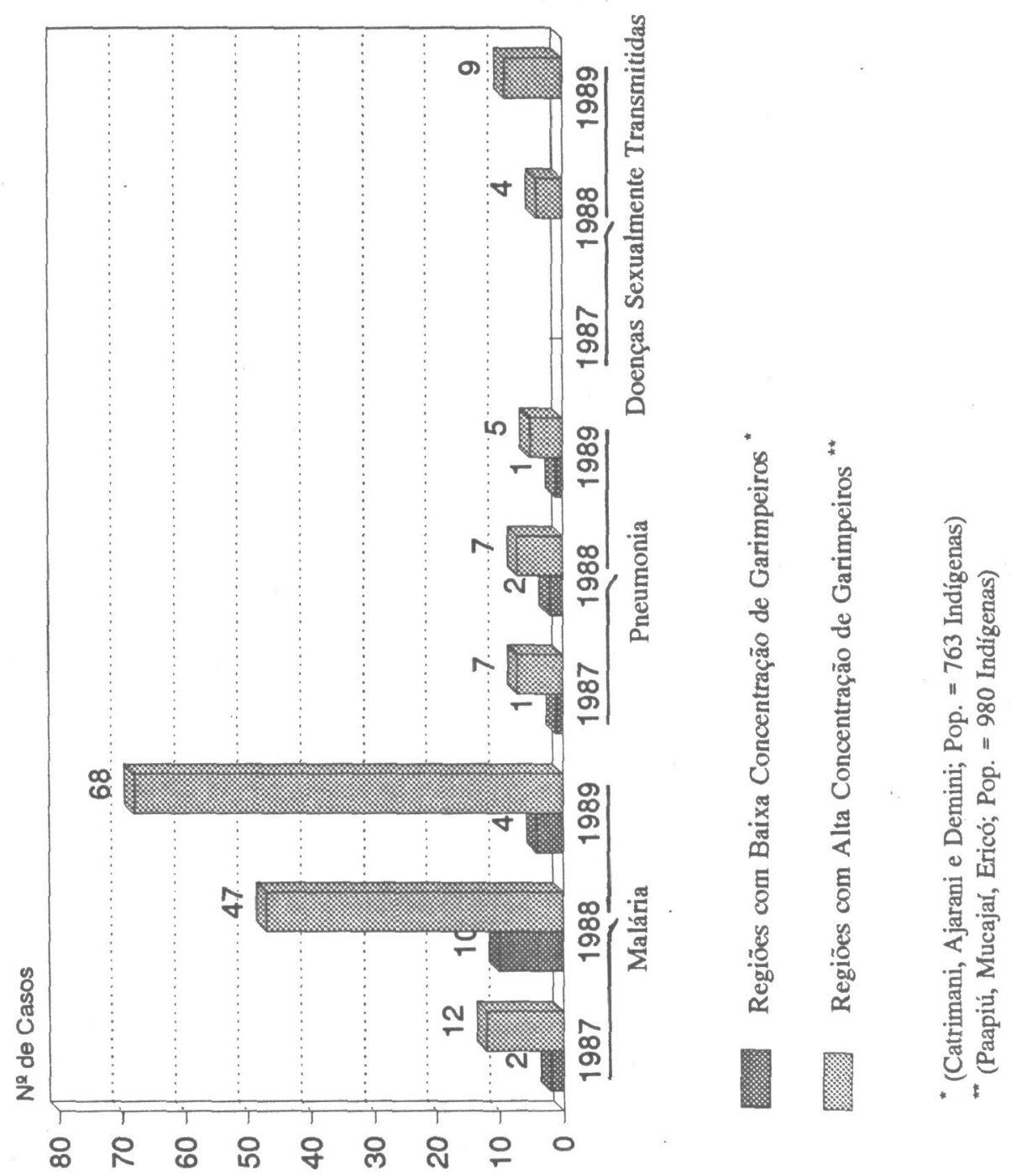


Com respeito à mortalidade de índios Yanomámi no triênio 1987/89 (Tabela III), observa-se que as principais causas de óbito foram aquelas cuja incidência aumentou em função das mudanças nas condições de vida condicionadas pelo garimpo. Assim é que a malária se destuca como a principal causa dentre os 114 óbitos verificarlus nos registros compilados. Deve ser notada, ainda, a participação das lesões externas (homicídios) como a $2^{2}$ causa em 1989 , refletindo a tendência geral observada no estado de Rorasıa a partir de 1988.

\section{TABELA III}

Distribuição de 114 Óbitos de Indígenas Yanomámi por Ano de Ocorrência e por Ordem Decrescente de suas Causas Imediatas

\begin{tabular}{|c|c|c|c|c|c|}
\hline 1987 & & 1988 & & $\begin{array}{c}\text { Até } \\
\text { AGO/1989 }\end{array}$ & \\
\hline $\mathrm{N}=30$ & $\%$ & $N=51$ & $\%$ & $N=33$ & $\%$ \\
\hline \multirow[t]{2}{*}{ Malária } & 23,3 & Malária & 33,3 & Malária & 39,3 \\
\hline & & $\begin{array}{c}\text { Afecçōes Mal } \\
\text { Defunidas }\end{array}$ & 21,5 & Homícidios & 18,8 \\
\hline Pneumonia & 23,3 & $\begin{array}{c}\text { Gastroenterite/ } \\
\text { Desidratação }\end{array}$ & 15,6 & $\begin{array}{c}\text { Gastroenterite/ } \\
\text { Desidratação }\end{array}$ & 12,2 \\
\hline $\begin{array}{c}\text { Afecçōes Mal } \\
\text { Definidas }\end{array}$ & 20,0 & $\begin{array}{l}\text { Deficiências } \\
\text { Nutricionais }\end{array}$ & 7,8 & Pneumonia & 9,0 \\
\hline $\begin{array}{c}\text { Gastroenterite/ } \\
\text { Desidratação }\end{array}$ & 13,3 & Preumonia & 3,9 & $\begin{array}{c}\text { Afecções Mal } \\
\text { Definidas }\end{array}$ & 6,0 \\
\hline $\begin{array}{c}\text { Afecçöes do } \\
\text { Periodo } \\
\text { Perinatal }\end{array}$ & 6,6 & Outras"* & 17,9 & Outras ${ }^{* * *}$ & 14,7 \\
\hline Outras* & 13,5 & & & & \\
\hline
\end{tabular}

* Homicídios = 1 caso; Embolia Pulmonar = 1; Insuficiência Renal = 1; Lesão por Esmagamento $=1$.

* Afecçōes Perinatais = 2 casos; Tuberculose $=1 ;$ Homicídio $=1$; Neoplasia do Figado $=1 ;$ Leucemia $=1 ;$ Hepatite $=1$; Cirrose do Figado $=1 ;$ Diabete $=1$.

*** Hemorragia Digestiva Aguda $=2$ casos; Tuberculose $=1$; Hepatite $=1 ;$ Afeç̧ăo Perinatal $=1$. 


\section{DISCUSSÃO}

Poucos são os relatos sobre a ocorrência de processsos mórbidos entre os Yanomámi no Brasil. O maior número de registros encontra-se em relatórios de programas assistenciais (CCPY, s/data; Brando, 1982; MDM/CCPY, 1984; CCPY, 1987) ou em algumas descriçōes de casos clínicos (Rees \& Shelley, 1976) e inquéritos sobre doenças específicas (Moraes et al, 1974, 1978; Carvalho, 1985; Carvalho et al, 1985; Oliver et al, 1975; Confalonieri et al, 1989).

Em relação à população Yanomámi localizada na Venezuela, que tem contato continuo com as aldeias do lado brasileiro, encontram-se também informações epidemiológicas decorrentes de programas assistenciais (Prog. Parima Culebra, s/data, a; b; 1990; Colchester, 1985), de investigações sobre processos epidêmicos localizados (Centerwall, 1968; Neel et al., 1970) e de inquéritos sorológicos (Soyano et al., 1976).

As informações nosológicas mais recentes sobre as aldeias do Brasil, especialmente aquelas localizadas em Roraima, foram obtidas durante uma operação emergencial de saúde, de origem governamental, levada a cabo no início de 1990 (Confalonieri, 1990; Menegola \& Albert, 1990), posteriormente atualizadas pelas equipes responsáveis pelas açōes de saúde que se seguiram (Pithan, 1990). Faltaram, no entanto, dados do perfil nosológico dos indígenas Yanomámi que vinham tendo acesso aos serviços governamentais de saúde localizados fora de seus territórios. Cabe assinalar que os dados ora apresentados refletem apenas parcialmente o quadre geral de morbidade e mortalidade da população Yanomámi do Brasil no periodo abarcado pelo estudo. Isto assim ceorte por resultarem da análise dos casos que puderam ser removidos para a cidade de Boa Vista no período mais crílico da disseminação dos processos infecciosos recóm-introduzidos. Mesmo assim, estes dados tiveram grande relevancia, pois se constituiram no primeiro alerta sobre a ocorrencia de severas epidemias resultantes das invasoes garimpxiras, em um momento em que o acesso à área Yanománi era estritamente controlado e restrito, sem haver plano de 
intervenção médico-sanitária abrangente ou equipes assistenciais lá permanentemente localizadas. Assim, a divulgação desses dados foi decisiva para o desencadeamento e orientação do Programa Emergencial de Assistência Sanitária aos Yanomámi - PEASY - no início de 1990.

Quanto à procedência dos casos internados na CIBV, verifica-se que a maioria vem de regiões de alta densidade de invasores, o que, sem dúvida, é reflexo da intensa transmissão de doenças infecciosas e parasitárias por eles desencadeada. Por outro lado, é também o reflexo parcial de um maior movimento de tráfego aéreo resultante da própria atividade garimpeira, que, em alguns momentos, facilitou a remoção de pacientes. Entretanto, algumas áreas com alta concentração de aldeias e duramente aungidas pelo garimpo, como, por exemplo, a da serra de Surucucus, foram pouco representadas entre os pacientes internados, não pela menor importância local dos agravos à saúde observados, mas sim pela maior dificuldade de tráfego aéreo devido à distância e às condições climáticas freqüentemente adversas. Além disto, deve-se ter em conta o menor contato dos habitantes da região com a sociedade envolvente e a conseqüente dificuldade em aceitar o deslocamento para a cidade. Por outro lado, a raridade das remoções oriundas das regiões com pouca ou nenhuma presença garimpeira deve-se à não-disseminação de patógenos alóctones nestas áreas. Deve ser notado que algumas delas dispõem de assistência permanente (Missão Religiosa, Posto da Fundação Nacional do Indio e acesso via transporte terrestre até Boa Vista).

A alta incidência de múltiplos agravos em índios Yanomámi é o reflexo direto da exposição simultânea a diversos agentes infecciosos até então ausentes nessa população. São bem conhecidos os efeitos deletérios, ìs vezes devastadores, da introdução de agentes infecciosos em comunidades isoladas, sem experiência prévia com os mesmos. Isto ocorre pelo não-desenvolvimento de proteção imune capaz de reduzir tanto as taxas de ataque nas epidemias quanto a gravidade clínica dos casos. Por outro lado, está historicamente provado que a pronta e eficaz intervenção médico-assistencial reduz a mortalidade em populações nestas situaçōes a níveis próximos dos observados em segmentos desfavorecidos da sociedade envolvente. 
Ademais, como elementos debilitantes, além do deficiente estado imunológico, devem-se agregar as carências nutricionais de caráter agudo e o estresse social resultante de novas relações de contato estabelecidas com os não-indios invasores, em condições extremamente adversas para os indígenas.

O fato de predominarem como principais causas de morbidade as doenças infecciosas e parasitárias é notório nas sociedades tribais mais isoladas. Algumas dessas doenças ocorrem de forma endêmica e sem grande impacto negativo, enquanto perdura o isolamento geográfico e cultural, devido ao longo período de adaptação às patobiocenoses com as quais estas populações se relacionam em seus territórios tradicionais. Com o contato abrupto e descontrolado com a sociedade envolvente, estes processos infecciosos tendem a se exarcerbar sob forma epidêmica, acrescidos às novas infeç̧ões introduzidas, iniciando um processo de rápida transição epidemiológica, caso o contato indiscriminado continue e, com isto, surjam mudanças culturais radicais.

A malária, que se revelou como a doença transmissível de maior impacto na morbi-mortalidade pós-invasão, ocorria de forma esparsa nas aldeias mais periféricas do território Yanomámi, não havendo transmissão autóctone nas áreas centrais do mesmo. A penetração dos grupos de garimpo, trazendo um grande número de suscetíveis à infecção malárica, além de individuos infectados, propiciou uma densidade populacional adequada à circulação do plasmódio. Outros fatores favorecedores da epidemia malárica foram os processos de modificação do ambiente natural, resultantes diretamente dos procedimentos empregados para a lavra do ouro. Estes envolvem o desvio e ampliação do curso de igarapés, com o conseqüente aumento da superfície de água e sua estagnação, favorecendo a proliferação anofélica. Deve ser notado, ainda, em relação à gravidade da malária, que ela decorre não só da demora no tratamento, mas também da alta prevalência de cepas de Plasmodium falciparum resistentes a quimioterápicos usuais nos garimpos amazônicos. As conseqüûncias disto foram 37 óbitos dentre os casos de malária ocorridos no período considerado e a necessidade de se instituir a transfusāo sangüínea em 17 pacientes por apresentarem 
anemia acentuada, o que aumenta o risco de disseminação de outras infecções, como a hepatite, AIDS, etc.

A grande freqüência de casos de infeccões respiratórias agudas resulta da introdução de agentes virais antes desconhecidos, principalmente a do resfriado comum e da gripe, sendo esta última freqüentemente agravada por pneumonias secundárias.

O pouco impacto causado por algumas infecções comuns da infância se deve à realização de programas de imunização, no periodo de 1982 - 1987, com boa cobertura vacinal nas aldeias de melhor acesso (CCPY, 1987).

A ocorrência de casos de doenças sexualmente transmissiveis, também consideradas epidêmicas, já que não ocorriam antes da invasão, deve-se à promiscuidade sexual com garimpeiros, resultantes da ruptura de costumes tribais, freqüentemente precedida de atos violentos.

Os casos de tuberculose registrados na CIBV certamente não refletem a situação real da população Yanomámi, devido à lenta evolução da doença, com manifestações menos evidentes de início, o que torna mais difícil o diagnóstico. A isto devem ser acrescentadas a falta de busca de casos $\mathrm{c}$ a ausência de cobertura prévia com BCG em muitas aldeias.

Associada à malária, a desnutrição $\mathrm{em}$ graus variados também sofreu aumento considerável e, por tomar os indivíduos mais vulneráveis a outros agravos de origem infecciosa, reveste-se de grande importância. A sua ocorréncia tem sido observada $\mathrm{em}$ situaçōes similares de contato intenso e súbito de comunidades semi-isoladas com a população majoritária. Neste sentido, é significativo que a maioria dos cassos alcondidos procedam da região do Paapiú, mais atingida pela ocupação. A sua principal causa é a depleção local de recursos alimentares tradicionais nas árcas invadidas. No caso da protcina animal, a fauna silvestre desaparece pelo excesso de caça pelos garimpeiros, alćm do ruido de motores e aviöes. Por outro lado, a pesca se toma difïcil en função da turvação das águas dos igarapés peles procedimentess de husca do ouro.

No que lange as alividades de produção agricola e colela, as mesmas lican scriamente projudicarlas pela incapacielarle relativa provocada pelo adoecer coletivo e pela desorganizaçäo das combundades, resullante da perda 
de vidas. Com este comprometimento do acesso às fontes tradicionais de subsistência, os hábitos alimentares sofrem modificações, já que a principal alternativa passa a ser o alimento industrializado levado por garimpeiros, principalmente como forma de cooptação, e que geralmente se constitui apenas de carboidratos.

Em relação aos dados de mortalidade, apesar do sub-registro, da dificuldade na coleta dos dados existentes e do pequeno número de casos estudados, ressalta-se o fato das principais causas de morte entre os Yanomámi, nos três últimos anos (Tabela III), estarem entre os agravos que tiveram sua incidência aumentada devido às radicais mudanças nas condições de vida resultantes do confronto com garimpeiros. A predominância geral das doenças infecciosas e parasitárias agudas como causas de óbito reflete o novo perfil epidemiológico surgido, bem como as falhas no processo assistencial. Da mesma forma, a proeminência da categoria "afecçōes mal definidas" resulta da ocorrência de óbitos sem assistência médica, além da impossibilidade de realização de diagnóstico post-mortem, por razões de natureza cultural.

Especialmente significativo é o fato de a causa "homicídios" figurar em segundo lugar, no ano de 1989 , entre os Yanomámi de Roraima, refletindo a tendência geral observada neste Estado a partir de 1988. Homicídios e acidentes de trânsito, como principais causas de mortalidade geral em Roraima, refletem uma deterioração da qualidade de vida e desorganização da sociedade como um todo. A imigração maciça e desordenada associada a graves alterações de comportamento, favorecidas pelo alto consumo de bebidas alcoólicas, facilitado pelo rápido aumento no dinheiro circulante, propicia a multiplicação de atos de violência. Esta, tendo se generalizado no Estado, atingiu a área indigena Yanomámi, resultando em cinco homicídios por armas de fogo em conflitos dos índios com garimpeiros, no ano de 1989, na região de Surucucus.

Os dados apresentados mostram claramente que a piora nas condiçōes de saúde dos grupos Yanomámi reflete a detcrioração na qualidade de vida dos mesmos, decorrente do impacto da atividade garimpeira em seu território. Sob o ponto de vista global, estas condiçōes significam um deplorível acréscimo ao quadro geral de endemias no pais, 
principalmente no que tange à malária e à tuberculose, além da possibilidade de disseminação de endemias localizadas, como a oncocercose, para outros Estados.

The change in the morbidity profile of the Yanomámi Indians admitted to the Casa do Indio, at Boa Vista, Roraima, from January 1987 to August 1989, is reported. The most frequent diseases observed in 495 patients were malaria, acute respiratory infections, tuberculosis, severe undernutrition, and sexually transmitted diseases. Malaria was the main cause of death of 114 Indians throughout the period. A striking increase in hospital admissions was noted in the population from the villages which were in closer contact with gold miners. The global impact of the invasion of the Yanomámi territory by miners on the quality of life and health levels of the Yanomami is discussed.

\section{AGRADECIMENTOS}

Expressamos nossos agradecimentos à Comissão pela Criação do Parque Yanomámi pelos meios proporcionados para a obtenção dos dados e sua análise.

\section{REFERENNCIAS BIBLIOGRÁFICAS}

BRANDO, R. B. - Boas Novas e Ericó - Relatório de Viagem, 1417 de junho/82. Mimeo, 9 pp., São Paulo, 1982.

CARVAlHo, J. J. M. - Estudo da Pressão Arterial de Indios Yanomámi. Tese de Doutorado, Faculdade de Medicina, Universidade Federal do Rio de Janeiro, 1985. 
CARVALHO, J. J. M.; LIMA, J. A. C.; CARVALHO, J. V. \& SOUZA, C. A. M. - Blood pressure is directly related to the degree of acculturation among primitive Yanomamo Indians. Circulation, 72 (Suppl. III): 296, 1985.

COMISSÃO PELA CRIAÇÃO DO PARQUE YANOMÁMI Relatórios de Saúde CCPY - Trabalhos médicos e odontológicos na área Yanomámi de 1985 a 1987. 2 Vols, 183 + 131 pp., mimeo, São Paulo, s/data.

COMISSÃO PELA CRIAÇĀO DO PARQUE YANOMÁMI Dez Anos de Trabalho. Mimeo, 80 pp., São Paulo, 1987.

CERTERWALL, W. R. - A recent experience with measles in a "Virginsoil" population. In: Biomedical Challenges presented by the American Indian, pp. 7-81, Scientific Publication $\mathrm{n}^{\circ}$ 165, Pan American Health Organization, Washington, 1968.

COLCHESTER, M., (Ed.) - The Health and Survival of the Venezuelan Yanomama. IWGIA, Copenhague, ARC/IWGLA, Document n 53, 104 pp., 1985.

CONFALONIERI, U. E. C.; FERREIRA, L. F. \& ARAUJO J. A. - Enteroparasitos em índios Yanomámi. Memórias do Instituto Oswaldo Cruz, 84 (Suppl IV): 111-113, 1989.

CONFALONIERI, U. E. C. - Saúde. pp 29-33 IN: Yanomámi: a todos os povos da terra. Ação pela Cidadania, 46 pp., 1990.

MEDECINS DU MONDE/CCPY - Dados e Sugestôes para um Programa de Assistência de Saúde na área Indigena Yanomámi. Mimeo, São Paulo, 66 pp + Anexos, 1984.

MENEGOLA, I. A. \& ALBERT, B. - Situação Sanitária dos Yanomámi do Paapiú: Relatório ne l, Mimeo, 9 pp., São Paulo, 1990.

MORAES, M. A. P. \& CHAVES, G. M. - Onchocerciasis in Brazil: New Findings among the Yanomama Indians. Bulletin of Pan American Health Organization, 8: 95-99, 1974.

MORAES, M. Ał. P., CHAVES, G. M. - Novas Observações sobre o foco de Oncocercose da Área do Rio Toototobi, Estado do Amazonas, Brasil. Boletin de la Oficina Sanitaria Panamericana, 84: 510-519, 1978.

NELI 1. W. V. et al - Notes on the effect of meales vaccine in d virgin-soil population of South American Indians. American Journal of Epidemiology, 91: 418-419, 1970.

OLIVER, W. J. ; COHEN. E. L. \& NEEL, J. V. - Blood pressure, Sodium Intake, and Sodium Related Hormones in the Yanomamo Indians, a "no-salt" Culture. Circulation, 52; 146-151, 1975.

PITHAN, O. A. - A Situação de Saúde dos Índios Yanomámi: Diagnóstico a partir da Casa do indio de Boa Vista, Roraima, 1987/l989. Mimeo, 16 pp., Boa Vista, 1989. 
- A Situação de Saúde dos Yanomámi de Roraima. Comunicação apresentada ao Simpósio Forest '90, Manaus, out/1989, Mimeo, 7 pp, 1990.

PROGRAMA PARIMA CULEBRA - Atención Primaria de Salud en el Alto Orinoco. Area de Influencia Yanomámi, mimeo, $28 \mathrm{pp}$., Caracas, s/data.

- Informe Anual de Actividade, Año 1986, Mimeo, 10 pp., Caracas, 1986.

- Informe Anual de Actividades, Año 1988, Mimeo 6 pp., Caracas, 1990.

REES, R. G. P. \& SHELLEY, A. J. - Estimativa quantitativa da resposta à clortetraciclina em um caso grave de desinteria por Balatidium coli. Acta Amazonica, 7: 47-49, 1976.

SOYANO, A.; MALAVE, R.; WALDER, R.; LAYRISSE, Z. \& LAYRISSE, M. - Hepatitis - B Atingen in an Isolated Indian Population (Yanomámi Indians) From Southern Venezuela. Revista Brasileira de Pesquisas Médicas e Biologicas, 9: 247-253, 1976. 